\title{
Electron Beam Additive Manufacturing with Wire
}

\author{
*Węglowski M and St Błacha S \\ Institute of Welding Poland
}

Received: 制January 29, 2018; Published: 眥 February 05, 2018

*Corresponding author: Marek Weglowski, Director's Plenipotentiary for Development of Research, Instytut Spawalnictwa (Institute of Welding), Bl. Czeslawa Str. 16-18, Gliwice 44-100

\section{Introduction}

Electron beam additive manufacturing with wire (EBAMW) is a novel technology which can directly fabricate 3-D near-net shape elements from metal wires. Of specific interest are the additive layer manufacturing processes with wires that are capable for producing fully dense metallic and hybrid parts in which the resulting parts may be used for loaded structure. This process is attractive because it eliminates contamination compare to powder process. Manufacturing near-net-shape elements layer-by-layer with wire as a deposit material offers a great potential for time and cost savings in comparison to conventional manufacturing technologies (such as casting, forging, etc.). The increasing market especially for aerospace industry demands for titanium, aluminum and other materials serial production parts has promoted wirefeed processes in recent years, as repeatability, material properties, material usage, possible part size, and building speed have also become issues.

Research carried out up to date was focused on the possibility of using EBAMW in space [1,2] and the ability to produce ready-made elements that meet the requirements of the space sector industry. Mitzner et al. [3] revealed that through the use of modulation of electron beam the refinement of the microstructure in the titanium alloy can be achieved. Gonzales et. al. [4] indicated that the use of flux cored wires containing aluminum, iron and boron allows manufacturing Ti-6Al-4V titanium alloys with a more stable and finer microstructure. The rapid prototyping process using a beam allows to produce a Ti-6Al-4V titanium airframe element at lower cost compared to older solution. The reduction of material consumption by $79 \%$ was achieved. The aim of the presented work was to carried out research on electron beam additive manufacturing with a stainless steel wire as a filler material. The scope of the work was to investigate the influence of selected EBAMW technological parameters such on stability of deposition process.

\section{Methodology}

The EBAMW process was conducted based on EB machine CVE XW150 model: 30/756 (Figure 1). The device is equipped with a wire feeder and a working chamber with a volume of $4.9 \mathrm{~m} 3$. The device is equipped with a system to monitor and record of the process parameters. The following parameters were applied during experimental tests: feeding angle $30^{\circ}$, working pressure $5 \bullet 10-5 \mathrm{mbar}$, beam current in the range of $1-30 \mathrm{~mA}$, accelerating voltage from 60 to $150 \mathrm{kV}$, wire feed rate from 600 to $3600 \mathrm{~mm} /$ min, travelling speed from 200 to $7000 \mathrm{~mm} / \mathrm{min}$. To an additive manufacturing specimens welding wire $1.2 \mathrm{~mm}$ in diameter (LNM307 Lincoln Electric: C 0.07\%, Mn 7.1\%, Si 0.8\%, Cr 18.6\%, Ni $8.0 \%$ wt.) was applied.
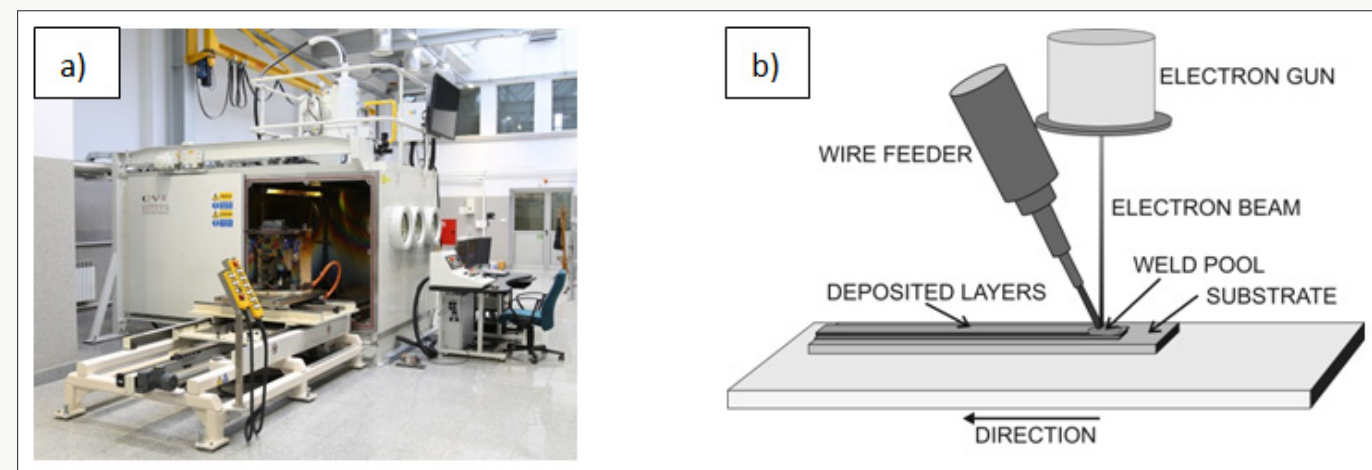

Figure 1: Electron beam additive manufacturing with wire set up a) EB machine b) scheme of the process. 


\section{Results and Discussion}

The scope of the work was to investigate the influence of technological parameters such as: wire feed rate, beam current, travelling speed, acceleration voltage on stability of the deposition process and geometric dimensions of the padding welds, single layer as well as whole structure. The research revealed that, at low beam currents, the deposition process is unstable. The padding weld reinforcement is non-uniform. Irregularity of the width, height and straightness of the padding welds can be observed. At too high acceleration voltage and beam current, burn-through of plate and excess penetration weld can be revealed. When the wire feed rate is too high, the amount of energy supplied is insufficient to stabilize the fusion process of the wire. The wire is deeper feeding into the welding pool and limits the possibility of creating of a channel. The increased volume of filler material flooded the channel and caused that the welding pool becomes wider.
The gained knowledge as well as results of preliminary experimental tests including study of influence of technological parameters on with and high of single padding welds allowed to produce the fully dense metallic parts based on electron beam additive manufacturing process with wire. The results are presented in Figure 2. The EBAM 307 steel plate was fabricated in a vacuum chamber. The deposited path was scanned in one direction. It means that the return movements in opposite direction were dead. The spacing between two adjacent tracks (overlap) was $1.3 \mathrm{~mm}$. The scanning directions were alternated layer to layer and the time interval is $2 \mathrm{~min}$. Eighteen layers were deposited and average height of each layer was approximately $1.0 \mathrm{~mm}$. The following technological parameters were applicable: accelerating voltage $U=60 \mathrm{kV}$, beam current $15 \mathrm{~mA}$, travelling speed $1000 \mathrm{~mm} /$ $\mathrm{min}$, wire feed rate $1000 \mathrm{~mm} / \mathrm{min}$, feeding angle $30^{\circ}$. Number of padding welds in one layer was 42 [5].

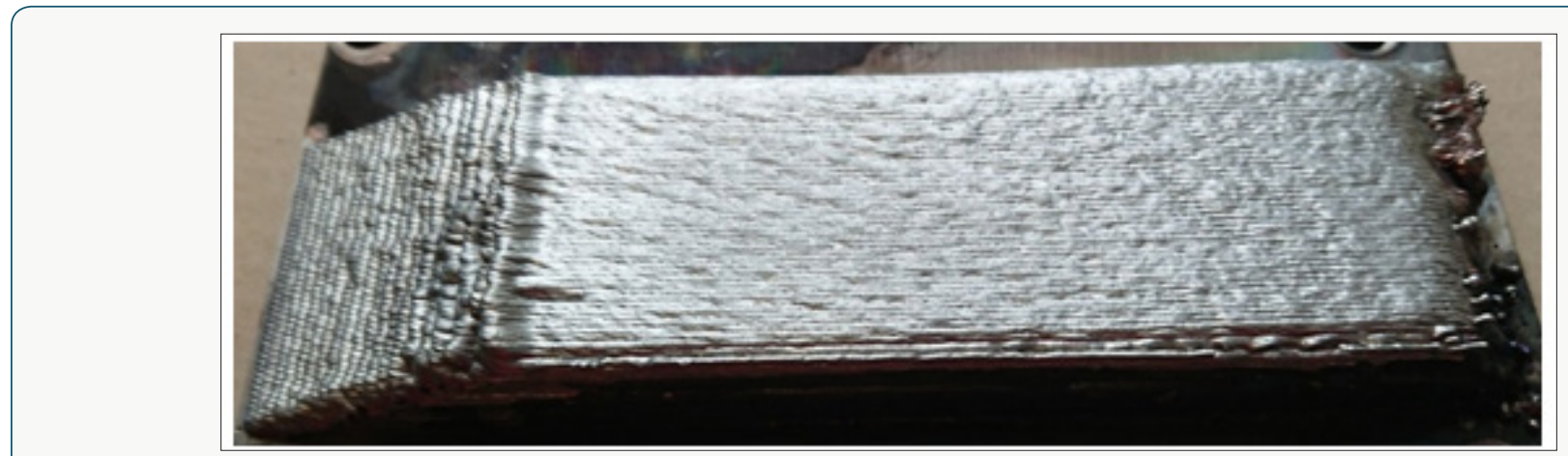

Figure 2: EBAMW final element, LNM 307 wire.

\section{References}

1. KMB Taminger, RA Harley, DL Dicus (2002). Solid Freeform Fabrication: An Enabling Technology for Future Space Missions. International Conference on Metal Powder Deposition for Rapid Manufacturing, San Antonio.

2. B Baufeld, R Widdison, $\mathrm{T}$ Dutilleu (2017) Electron beam additive manufacturing: deposition strategies and properties. International Electron Beam Welding Conference, Aachen 114-117.
3. S Mitzner, S Liu (2012) Grain Refinement of Freeform Fabricated Ti-6Al$4 \mathrm{~V}$ Alloy Using Beam/Arc Modulation. Proceeding of the $23^{\text {rd }}$ Annual International Solid Freeform Fabrication Symposium 536-555.

4. D Gonzales, S Liu (2016) Using Powder Cored Tubular Wire Technology to Enhance Electron Beam Freeform Fabricated Structures.TMS $145^{\text {th }}$ Annual Meeting \& Exhibition 183-189.

5. S Phinazee (2007) Efficiencies: Saving time and money with electron beam free form fabrication. Fabricator 15-20.

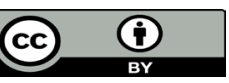

This work is licensed under Creative Commons Attribution 4.0 License

To Submit Your Article Click Here: Submit Article

DOI: 10.32474/TCEIA.2018.01.000106

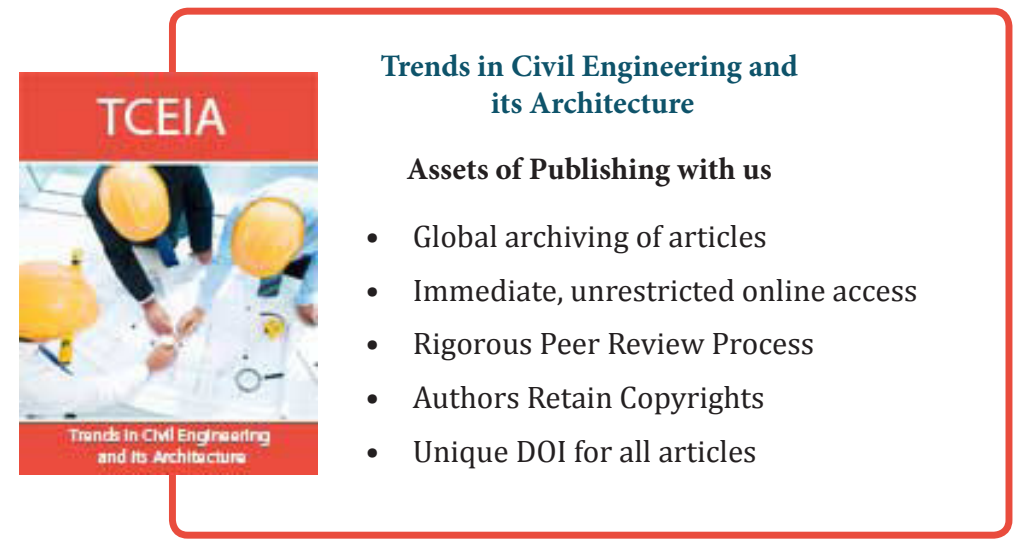

